\title{
ITF

\section{Research on the specific movement of the head in tennis strokes}

\author{
Manuel Fernández López
}

\section{ABSTRACT}

Technique is one of the aspects that has the most relevant influence on tennis player performance. Searching for more efficient and effective technique, by means of the application of biomechanical laws, is a constant among coaches and researchers. This article deals with a very concrete subject in tennis technique: the position of the head during the impact phase of tennis strokes. Biomechanical aspects of the strokes will also be considered, as well as other relevant aspects such as fixing the gaze during the stroke and the stretching-shortening cycle.
Key words: vision, balance, fixing, impact.

Received: 29 January 2020

Accepted: 19 February 2020

Corresponding author: Manuel

Fernández López, Spain. Email: tennisplus.manu@gmail.com

\section{INTRODUCTION}

Certain studies carried out with professional players, both male and female, suggest that fixing the head during all or part of the impact phase in a tennis stroke is an important factor for the correct execution of tennis strokes, determining performance through stability during this execution (Lafont, 2008).

Heightened balance/stability of vision or the head occurs at three points in the game: first, during the gaze when receiving information when reading the sent by the opponent (for example, the flight of the ball); second, focusing when the ball moves into the player's impact zone; and third, fixating on the impact point, keeping the eye-head stability during and even after impact (Elliott, Reid, \& Crespo, 2009).

The support base will help to keep the right alignment of the spine and, in turn, it will help to keep the head up. The lack of balance, an incorrect execution of the movement, or a wrong position will make achieving head stability difficult at impact, and therefore, will reduce the possibility of an efficient stroke.

\section{ITS RELEVANCE FOR TENNIS}

The biomechanics of tennis strokes is a field of great importance for coaches and researchers. Several studies have specifically dealt with the function of the head: for example its position during play (Elliott et al., 2003, 2009); and, its relationship with the gaze. Lebeau et al. (2016) studied the "quiet eye" concept, taken from Vickers (2016), who observed the relationship between the position of the head, the direction of the gaze and the attention of the athletes or persons being studied. In tennis, research done by authors such as Reina, Moreno, \& Sanz (2007); Sáenz-Moncaleano, Basevitch, \& Tenenbaum (2018) and Giblin, Whiteside, \& Reid (2017), among others, is worth mentioning.

On the other hand, head movements can be related to the stretching-shortening cycle of the upper limbs; moving the head slightly forward, away from the shoulder, facilitates the creation of the pre-stretching movement that will provide power to the arm and the racket. Because of this, most probably, beginner level children and less experienced players may move their heads when hitting.

For this reason, it is suggested that it is necessary to train the eye-head fixation at impact, so as to avoid potentially harmful movements (Elliot, et. al., 2009). In this same vein, Lafont (2007; 2008) states that it is probable that inexperienced players try to see if the ball goes to the desired target, and because of this, they do not fix their head on the impact zone, as elite players do.

When comparing the technical movements in Nadal's and Federer's strokes, which are now considered the best ever, we find a number of differences between them; however, there is an aspect in which they both coincide: they fix the gaze and the head on the impact point, and maintain it after the stroke, during the follow through. Unlike other lower level players, these two do not try to see if the ball goes towards the target they were aiming at (Lafont, 2008). 


\section{MOST RELEVANT RESEARCH}

Research can be classified according to the most relevant content types researched:

Research with subjective or qualitative observation of the head at impact

Keller et al., (2006) subjectively evaluated the body position of participants (children), classifying their styles using different tests. One of the tests involved hitting a forehand with a mini-tennis racket with the body position being observed and evaluated (it being explained in the study that particular attention would be placed on evaluation of the horizontal position of the player's feet, the low centre of gravity and the straight position of the back and the head). Also, the test scored the accuracy of strokes, relating the outcome and biomechanical variables. The results suggest that the most efficient kids are classified as reflective in their style, performing more mature movements and skills.

Among other subjective observations are the ones made by Lafont $(2007,2008)$ which used photographs of the head positions of professional tennis players at the point of impact. This author has classified players into: "fixers, partial fixers and non-fixers", depending on whether they fixed their heads more or less at impact. Results concluded that most professional players were at least partial fixers, even though the exact zone near the impact zone where they fixed, varied considerably from player to player. The duration of the maintenance of fixation after impact helped to differentiate elite players from professional players.

Research of biomechanics or quantitative analysis of the head position at impact

A study by Shafizadeh et al. (2019) has implications for perfecting the movement of the tennis serve. The author gathered all movements in a full biomechanical model with various degrees of freedom, quite an innovative procedure given that it would allow subsequent analysis to be performed from either a general perspective or a more specific point of view for each joint or axis. So far, much biomechanics research has focused on and has made a great deal of progress in stroke mechanics, measuring the speed of the joints, the racket, the ball, even in the global movements in the rotation of the trunk, the leg drive, or both, in many cases using markers and 3D records (see Bačić \& Hume (2018) for all. However, in many studies, the position and orientation of the head were not considered, and neither was accuracy of the strokes, i.e. measured with targets in different contexts during play.
Quantitative research related to ocular movement

The gaze in the strokes is a very important aspect. Giblin et al., (2016), observed that when testing players who were serving with closed eyes, there were significant stroke differences in the ball toss and racquet kinetics from the backswing to the final phase, with misses in 16 out of the 24 services intended. Furthermore, and contrary to the hypothesis, the speed of the movement of the racket decreased when compared to those serves with open eyes. This study intended to prove if the service is a closed skill, as had been normally commented; but it is quite the opposite according to the results, since if it were closed, it could be performed very well by top level competition players as the participants of the study.

Luis del Campo et al. (2015), whilst studying the visual search, observed and classified the vision of the ball into four phases both in lab conditions and court conditions: A) the ball leaving the ball machine to entering the player's field of vision; B) the moment the ball enters the players field of vision to the bounce; C) from the bounce to shot contact; and D) from the contact to the moment the ball leaves the player's field of vision. The fact that the ball becomes the most important spacial location in all phases (except phase D) highlights the role of the gaze in these phases, in which fixation is based around intercepting the ball, according to some studies of different sports (Lebeau et al., 2016).

Reina et al. (2006), in a previous study with wheelchair tennis players and players standing on two feet, found in the observed D phase in their study (from impact in service until the ball bounces on court) that there were a greater number of fixations in zones ahead of the ball for wheelchair tennis players, compared with standing players who had a greater number of fixations in zones behind the flight of the ball.

Reina et al., (2007), when comparing the gaze of expert to beginner wheelchair players relative to visual search behaviour during an opponent's serve, noted a greater number of fixations on the ball in general from beginners, obtaining a significant difference at the time of opponent impact where experts, when compared to beginners, made a greater number of fixations on the server's racket rather than the ball. In turn, beginners fixated more on the ball. The authors suggest that the difference could be due to the fact that experts anticipate more on the area of the bounce of the ball from the stroke, since they predict the resultant direction, speed, effect or height of the ball more accurately, whereas this prediction is still lacking in beginners.

In different lab studies concerning the vision of and movement response to opponent strokes (Singer, Cauraugh, Chen, Steinberg, Frehlich, 1996; Ward, Williams, Bennett, 2002), the differences between expert and beginner tennis players were analysed. Singer et al. (1996) showed that beginners fixated more on the head of their opponents but that the experts' movement were faster and more accurate. Ward et al. (2002) showed in their study that the decision time from the expert group decreased less than the beginner group's did when moving from a normal image to an obscured image, signalling better anticipation for the expert group 
given that experts may require more minimal information for successful performance.

Williams, Ward, Knowles, Smeeton (2002) followed the same research line to support their previous research, to develop an on-court test based on results obtained from the lab. The outcome of the lab in lab conditions, involving tennis video clips watched by the participants, conclude that 2D observation makes it difficult to predict the flight of a ball, due to the lack of depth, even when dealing with experienced players (Taya, Windridge, Osman, 2013).

Quevedo et al., (2015) studied competitive tennis players and observed how saccadic service movements in a non-specific task improved with programmed training by means of a 3D training system of different visual skills.

On the other hand, Ducrocq et al., (2016; 2017) suggested that the eye/head fixation impacts on the attention to play towards a target when under pressure, after training for it. These investigations are based on studies like Lafont's (2007; 2008), which have already been mentioned, which state there is a direct relationship between the position of the head being oriented towards the impact zone and maintaining stability during and after impact, with the level of elite professional players.

Along the same lines, Sáenz-Moncaleano et al. (2018) examined the "gaze behaviour", that is, differences in fixations on the flight of the ball and QE (Quiet Eye) between intermediate and higher-level tennis players. According to the authors, this has been the first approach to study the gaze behaviour in the rest of the service in situ. Higher level players proved to make better returns than lower level players. Furthermore, the scores of these players when hitting the targets was characterized by longer fixations in the bounce zone just before the ball arrived. Higher level players managed to have longer QE duration and scored higher in the strokes in this same group.

\section{CONCLUSIONS}

The first conclusion refers to the scarce amount of research that exists on the function of the head and the "QE", "gaze" or "saccades" at the time of impact, and mainly in real game conditions.

Another important conclusion has to do with the use of technological advances that make it possible to measure specific movements. These measurements centre on the impact phase and are combined with measurements of stroke accuracy, so as to link the target, the movement performed, the gaze and the fixation on the same phase.

Finally, it is necessary to discuss the importance of research on the gaze and the head at impact in tennis strokes, and how the fixation and stabilization of these two factors seems to be key in the outcome and accuracy of the execution.
The research mentioned above concluded that higher level players can better manage all the movements of the kinetic chain, and consequently, they fix the eyes and the head ("gaze behaviour") on the impact zone to keep the accuracy levels extremely high.

\section{REFERENCES}

Bačić, B., \& Hume, P. A. (2018). Computational intelligence for qualitative coaching diagnostics: Automated assessment of tennis swings to improve performance and safety. Big Data, 6(4), 291-304. https://doi.org/10.1089/big.2018.0062

Ducrocq, E., Wilson, M., Vine, S., \& Derakshan, N. (2016). Training attentional control improves cognitive and motor task performance. Journal of sport and exercise psychology, 38(5), 521-533, https://doi.org/10.1123/jsep.2016-0052

Ducrocq, E., Wilson, M., Smith, T. J., \& Derakshan, N. (2017). Adaptive working memory training reduces the negative impact of anxiety on competitive motor performance. Journal of Sport and Exercise Psychology, 39(6), 412-422, https://doi.org/10.1123/isep.2017-0217

Elliott, B., Reid, M. \& Crespo, M. (2009). El desarrollo de la técnica en la producción de los golpes de tenis. ITF The international tennis federation, Ed. Primera.

Elliott, B. C., Reid, M. \& Crespo, M. (2003). Biomechanics of advanced tennis. ITF The international tennis federation, Ed. Primera.

Giblin, G., Whiteside, D. \& Reid, M. (2017). Now you see, now you don't ... the influence of visual occlusion on racket and ball kinematics in the tennis serve. Sports Biomechanics, 16(1), 23-33, https://doi.org/10.1080/14763141.2016.1179337

Keller, J., Ripoll, H. (2006). Trends in learning research, chapter 7, pp. 139-170.

Lafont, D. (2007). Towards a new hitting model in tennis. International Journal of Performance Analysis in Sport, 7(3), 106-116, https://doi.org/10.1080/24748668.2007.11868414

Lafont, D. (2008). Gaze control during the hitting phase in tennis: a preliminary study. International Journal of Performance Analysis in Sport, 8(1), 85-100, https://doi.org/10.1080/24748668.2008.11868425

Lebeau, J. C., Liu, S., Sáenz-Moncaleano, C., SanduveteChaves, S., Chacón-Moscoso, S., Becker, B. J., \& Tenenbaum, G. (2016). Quiet eye and performance in sport: A meta-analysis. Journal of Sport \& Exercise Psychology, 38(5), 441-457, https://doi.org/10.1123/jsep.2015-0123

Luis del Campo, V., Reina, R., Sabido, R., \& Moreno, F. J. (2015). Diferencias en el comportamiento visual y motor de tenistas en laboratorio y en pista de tenis. Revista Latinoamericana de Psicología, 47(2), 136-145, https://doi.org/10.1016/i.rlp.2015.05.003

Quevedo, LL., Padros, A., Sole, J., \& Cardona, G. (2015). 
Perceptual-cognitive training with the Neurotracker 3DMOT to improve performance in three different sports. Apunts, educación física y esports, 119. pp. 97-108.

Reina, R., Moreno, F., Sanz, D., Damas, J., \& Luis, V. (2006). El efecto de la dimensionalidad de la escena en el comportamiento visual y motor durante el resto al servicio en tenis y tenis en silla de ruedas. European Journal of Human Movement, (16), 63-83.

Reina, R., Moreno, F. J., \& Sanz, D. (2007). Visual behavior and motor responses of novice and experienced wheelchair tennis players relative to the service return. Adapted physical activity quarterly (Vol. 24), https://doi.org/10.1123/apaq.24.3.254

Sáenz-Moncaleano, C., Basevitch, I., \& Tenenbaum, G. (2018). Gaze behaviors during serve returns in tennis: a comparison between intermediate-and high-skill players. Journal of Sport \& Exercise Psychology. Volume 40: Issue 2, Pages: 49-59, https://doi.org/10.1123/jsep.2017-0253

Shafizadeh, M., Bonner, S., Fraser, J., \& Barnes, A. (2019).

Effect of environmental constraints on multi-segment coordination patterns during the tennis service in expert performers. Journal of sports sciences, 37(9), 1011-1020, https://doi.org/10.1080/02640414.2018.1538691

Singer, R. N., Cauraugh, J. H., Chen, D., Steinberg, G. M., \& Frehlich, S. G. (1996). Visual search, anticipation, and reactive comparisons between highly-skilled and beginning tennis players. Journal of Applied Sport Psychology, 8(1),

9-26, https://doi.org/10.1080/10413209608406305

Taya, S., Windridge, D., \& Osman, M. (2013). Trained eyes: Experience promotes adaptive gaze control in dynamic and uncertain visual environments. PLoS One, 8(8), https://doi.org/10.1371/journal.pone.0071371

Vickers, J. N. (2016). The quiet eye: origins, controversies, and future directions. Kinesiology Review, 5(2), 119-28, https://doi.org/10.1123/kr.2016-0005

Ward, P., Williams, A. M., \& Bennett, S. J. (2002). Visual search and biological motion perception in tennis. Research Quarterly for Exercise and Sport, 73(1), 107-112, https://doi.org/10.1080/02701367.2002.10608997

Williams, A. M., Ward, P., Knowles, J. M., \& Smeeton, N. J. (2002). Anticipation skill in a real-world task: measurement, training, and transfer in tennis. Journal of Experimental Psychology: Applied, 8(4), 259, https://doi.org/10.1037/1076-898X.8.4.259
RECOMMENDED ITF TENNIS ACADEMY CONTENT (CLICK BELOW)

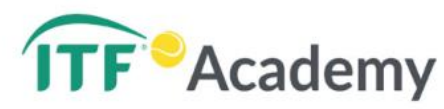

Copyright (c) 2020 Manuel Fernández López

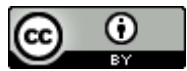

This text is under a Creative Commons BY 4.0 license

\begin{abstract}
You are free to Share - copy and redistribute the material in any medium or format - and Adapt the content - remix, transform, and build upon the material for any purpose, even commercially under the following terms:

Attribution: You must give appropriate credit, provide a link to the license, and indicate if changes were made. You may do so in any reasonable manner, but not in any way that suggests the licensor endorses you or your use.
\end{abstract}

CCBY4.0 license terms summary CCBY4.0 license terms 